\title{
Light Robotics: Aiming towards all-optical nano-robotics
}

\author{
Glückstad, Jesper; Palima, Darwin; Bañas, Andrew
}

\section{Published in:}

Proceedings of SPIE

Link to article, DOI:

$10.1117 / 12.2270422$

Publication date:

2017

Document Version

Publisher's PDF, also known as Version of record

Link back to DTU Orbit

Citation (APA):

Glückstad, J., Palima, D., \& Bañas, A. (2017). Light Robotics: Aiming towards all-optical nano-robotics. In T. Omatsu, \& R. Morita (Eds.), Proceedings of SPIE (Vol. 10252). [102520C] SPIE - International Society for Optical Engineering. Proceedings of SPIE - The International Society for Optical Engineering https://doi.org/10.1117/12.2270422

\section{General rights}

Copyright and moral rights for the publications made accessible in the public portal are retained by the authors and/or other copyright owners and it is a condition of accessing publications that users recognise and abide by the legal requirements associated with these rights.

- Users may download and print one copy of any publication from the public portal for the purpose of private study or research.

- You may not further distribute the material or use it for any profit-making activity or commercial gain

- You may freely distribute the URL identifying the publication in the public portal 


\title{
Light Robotics: Aiming towards all-optical nano-robotics
}

\author{
Jesper Glückstad $^{1,2}$ Darwin Palima ${ }^{1}$ Andrew Banas $^{2}$ \\ ${ }^{1}$ DTU Fotonik, Dept. of Photonics Engineering \\ Techn. University of Denmark, Ørsted Plads 343 \\ DK-2800 Kgs. Lyngby, Denmark \\ ${ }^{2}$ OptoRobotix ApS, DK-2000 Frederiksberg, Denmark \\ *Email: jesper.gluckstad@fotonik.dtu.dk \\ www.ppo.dk www.GPCphotonics.com www.OptoRobotix.com
}

\begin{abstract}
Light Robotics is a new field of research where ingredients from photonics, nanotechnology and biotechnology are put together in new ways to realize light-driven robotics at the smallest scales to solve major challenges primarily within the nanobio-domain but not limited hereto. Exploring the full potential of this new 'drone-like' light-printed, light-driven, light-actuated micro- and nanorobotics in challenging geometries requires a versatile and real-time reconfigurable light addressing that can dynamically track a plurality of tiny tools in 3D to ensure real-time continuous lightdelivery on the fly. Our latest developments in this new and exciting research area will be reviewed.
\end{abstract}

Keywords: light-driven robotics, nano-fabrication, optical tracking, holography, GPC, Holo-GPC

\section{INTRODUCTION}

The 2014 Nobel Prize in Chemistry was celebrating the breaking of the classical far-field microscopy diffraction entering the sub-wavelength regime providing optical resolutions down to a few nanometers (hence coined 'optical nanoscopy'). Closely related to this breakthrough is the rapidly emerging field of light-based 3D micro- and nano-printing grounded on powerful approaches offered by e.g. nonlinear photo-polymerization also now reaching resolutions down to a few tens of nanometers. A final scientific accomplishment - namely the invention of optical trapping, optical manipulation and optical tweezing - a triangulation of new functionalities can be achieved, required for true Light Robotics.

Step by step we are beginning to see the many intriguing possibilities of directly equipping 3Dprinted Light Robotics equipped with multi-functional nanoprobes, nanotips or nanotapers fabricated 
with true nanoscopic resolution. The uniqueness of this approach is that even if a user aims at exploring e.g. micro-biology at subcellular scales, the main support of each Light Robotic structure can be designed with size and shape that allows convenient manipulation with even moderate NA objective lenses. Each Light Robotic structure is printed with convenient micron-sized spherical "handles" that allow for volumetric laser-manipulation with six-degrees-of-freedom (6-DOF) and in full real-time. Thereby, a drone-like functionality can be obtained which can almost provide the user with the sensation of stretching one's hands directly into the cellular micro-environment with the ability to interact with the live specimen directly while observing in full 3D.
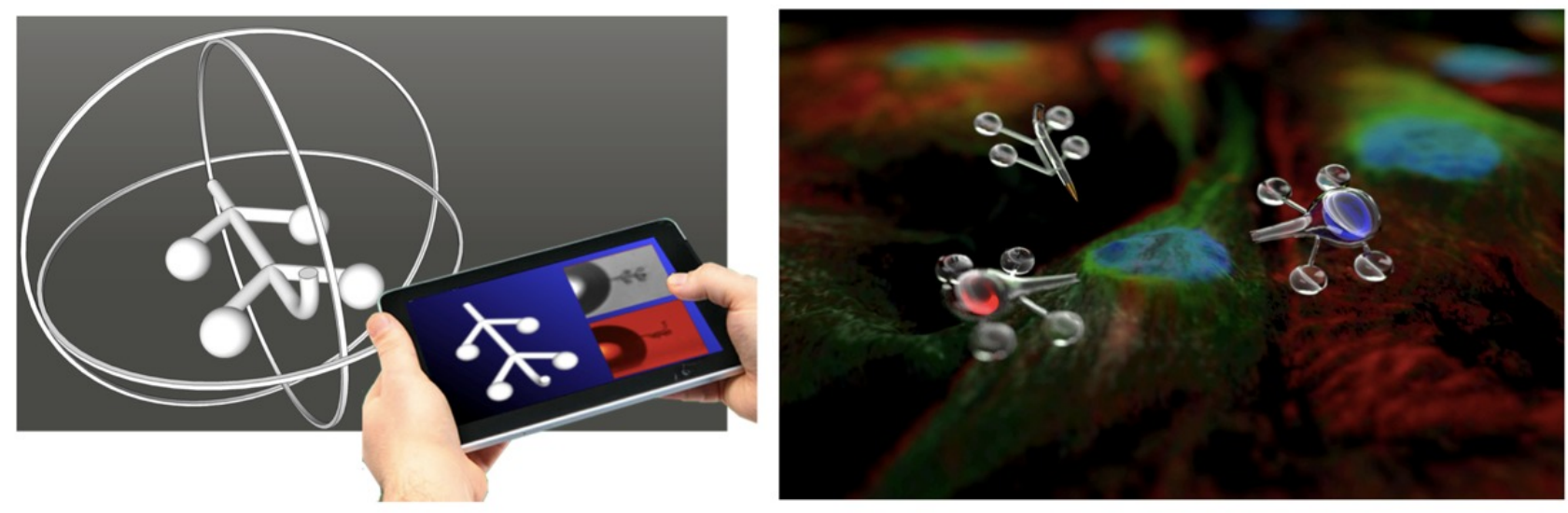

Fig. 1: Light Robotics with 3D real-time drone-like functionality in a microscopic environment

As demonstrated in pioneering experiments by Arthur Ashkin and his team at Bell Labs in the early 70es [1], harnessed into stable optical tweezing demonstrations in the mid 80es, focused laser light is able to exchange momentum with small refractive particles and make these seek toward the laserbeam foci and thereafter stay stable with strongly reduced Brownian motions. This takes best place in aqueous solutions in which living cells and other micro-organisms can be sustained and thrive in a relatively natural environment and also the liquid provides inherent cooling of the laser trapped particles and is giving a helping hand in damping Brownian fluctuations. Thanks to these pioneering achievements we can today create almost ideal conditions for most of the functionalities required to embody real-time 3D and true 6-DOF Light Robotics [2-10]. An example of Light Robotics in action is illustrated in Fig. 1 above and Fig. 2 below. 


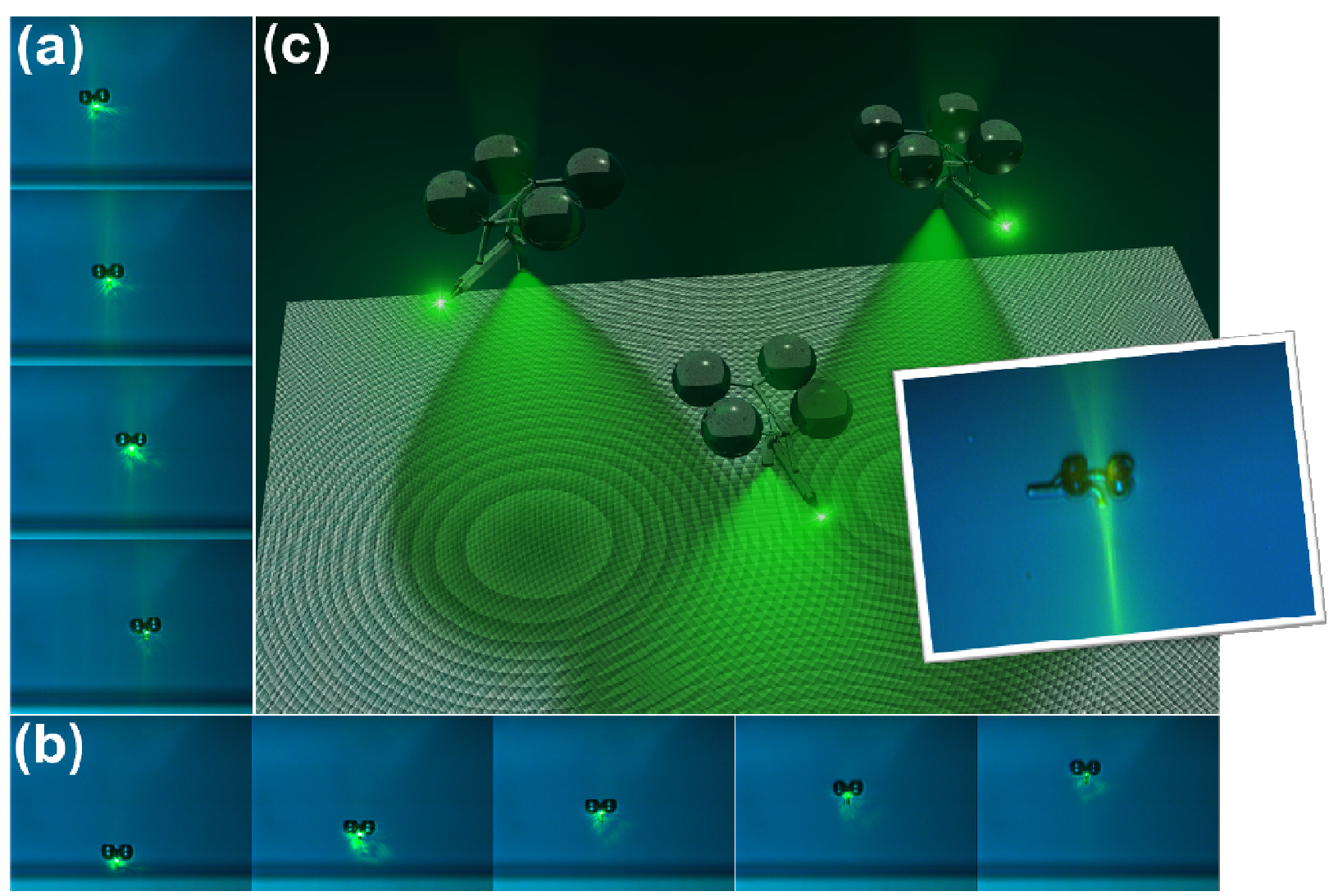

Fig. 2: 3D light tracking a plurality of Light Robotic structures. Adapted from ref. [9].

\section{LIGHT ROBOTICS IN ACTION}

Using contemporary two-photon polymerization we can directly 3D-print a plurality of Light Robotic structures equipped with nanoprobes, nanotips and nano-tapers with high resolution and fidelity. This is unique since a user can perform active cell biology interactions at tiny scales even though the main structure has a size and shape that allows convenient microscopic observation and laser manipulation with moderate numerical aperture optics. Some of our earlier experimental demonstrations are illustrated below. We have demonstrated simultaneous top and side-view imaging giving the required 3D sensation when navigating the microscopic tools in a volume in realtime and with 6-DOF. 


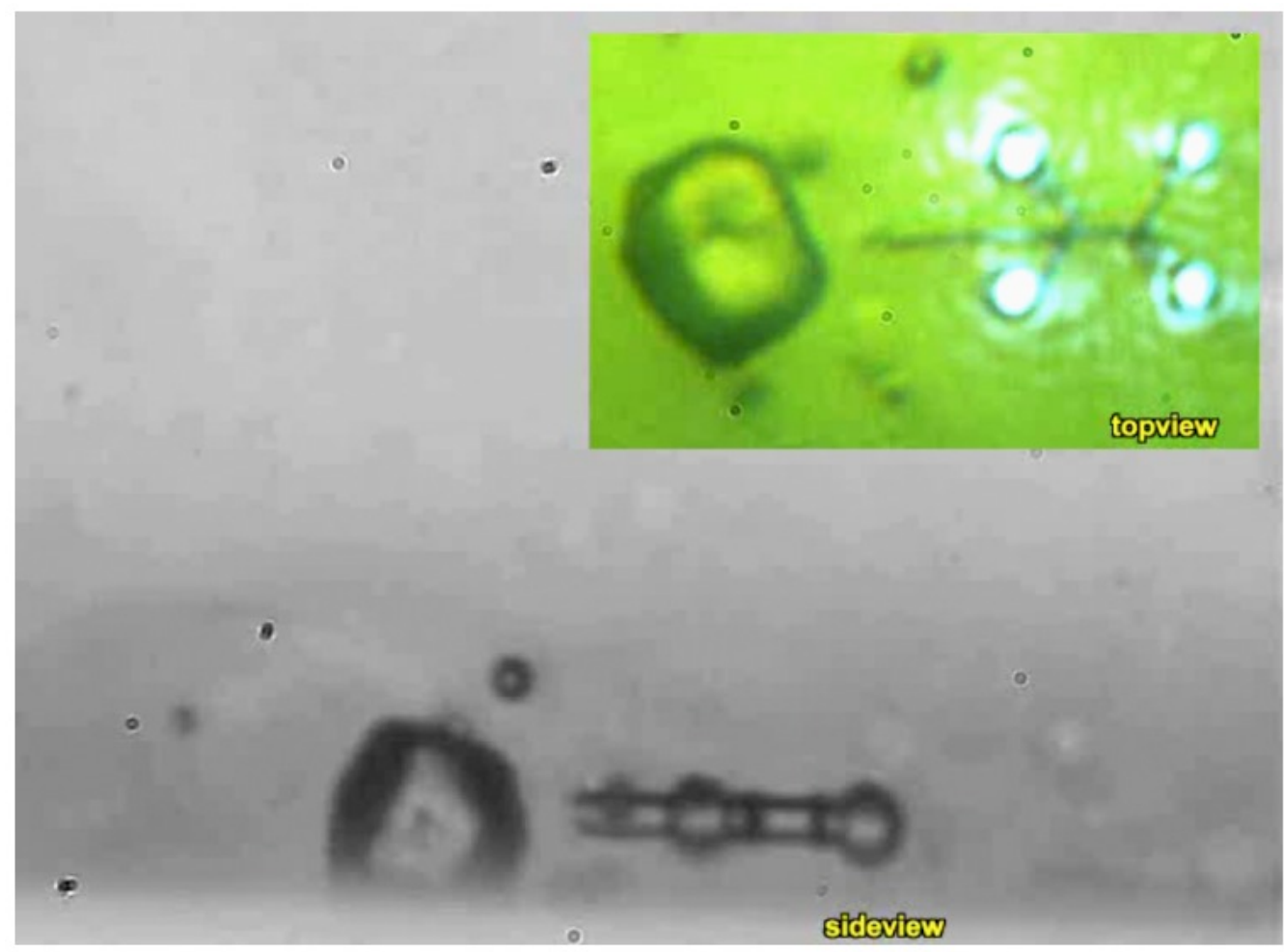

Fig. 3: Light Robotic probing from top and side showing an opto-mechanical probe-interaction with a tiny surface-positioned object. Adapted from refs. [3,4].

As is evident from Fig. 3 each Light Robotic structure is typically equipped with a number of optical "handles" that allow for real-time 3D drone-like interaction with 6-DOF when user-controlled via a joystick or a similar intuitive gaming device. It is also possible to fabricate light-guiding tools so that targeted and real-time coupled light [11-16] can be used as near-field irradiating and receiving nanotorchs i.e. Fig. 4.
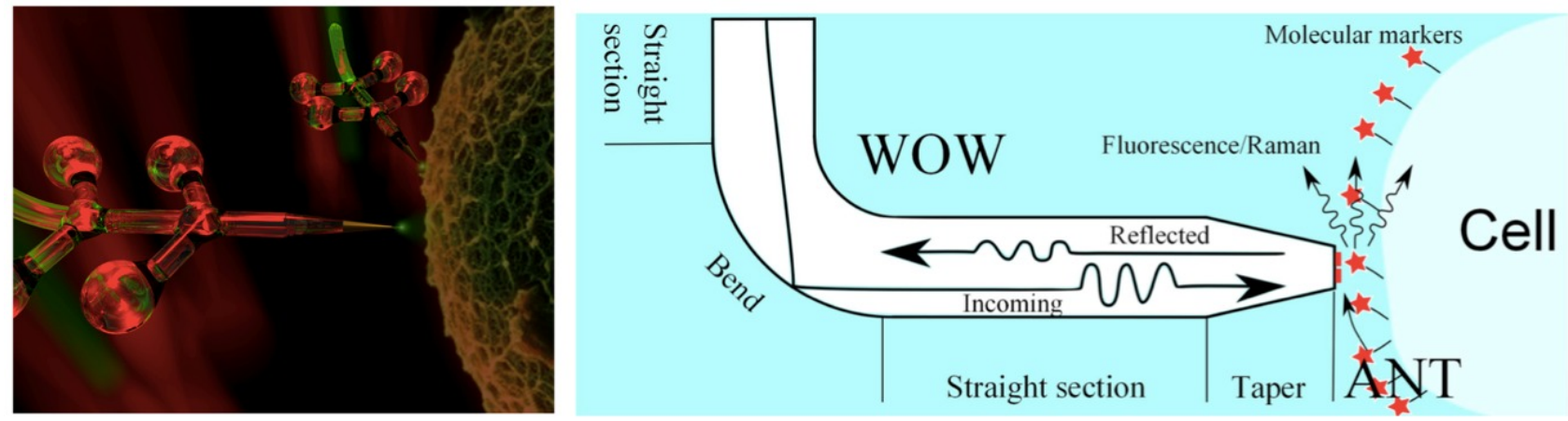

Fig. 4: Light Robotic tool equipped with an integrated waveguide structure to act as an optical nearfield probe for e.g. tip-enhanced Raman signal acquisition. Adapted from Ref. [8]. 
Hence, the Light Robotic structures can tact as "drone-like" controlled free-floating probes to monitor micro-biologic processes and provide spatially targeted mechanical, chemical or even optical stimuli that would otherwise be very difficult to achieve in a full micro-biologic environment. For example, a Light Robotic tool can be envisioned to perform measurement operations of receptors on a cell membrane and potentially even use the cell signaling network to initiate biochemical processes within the cell itself.
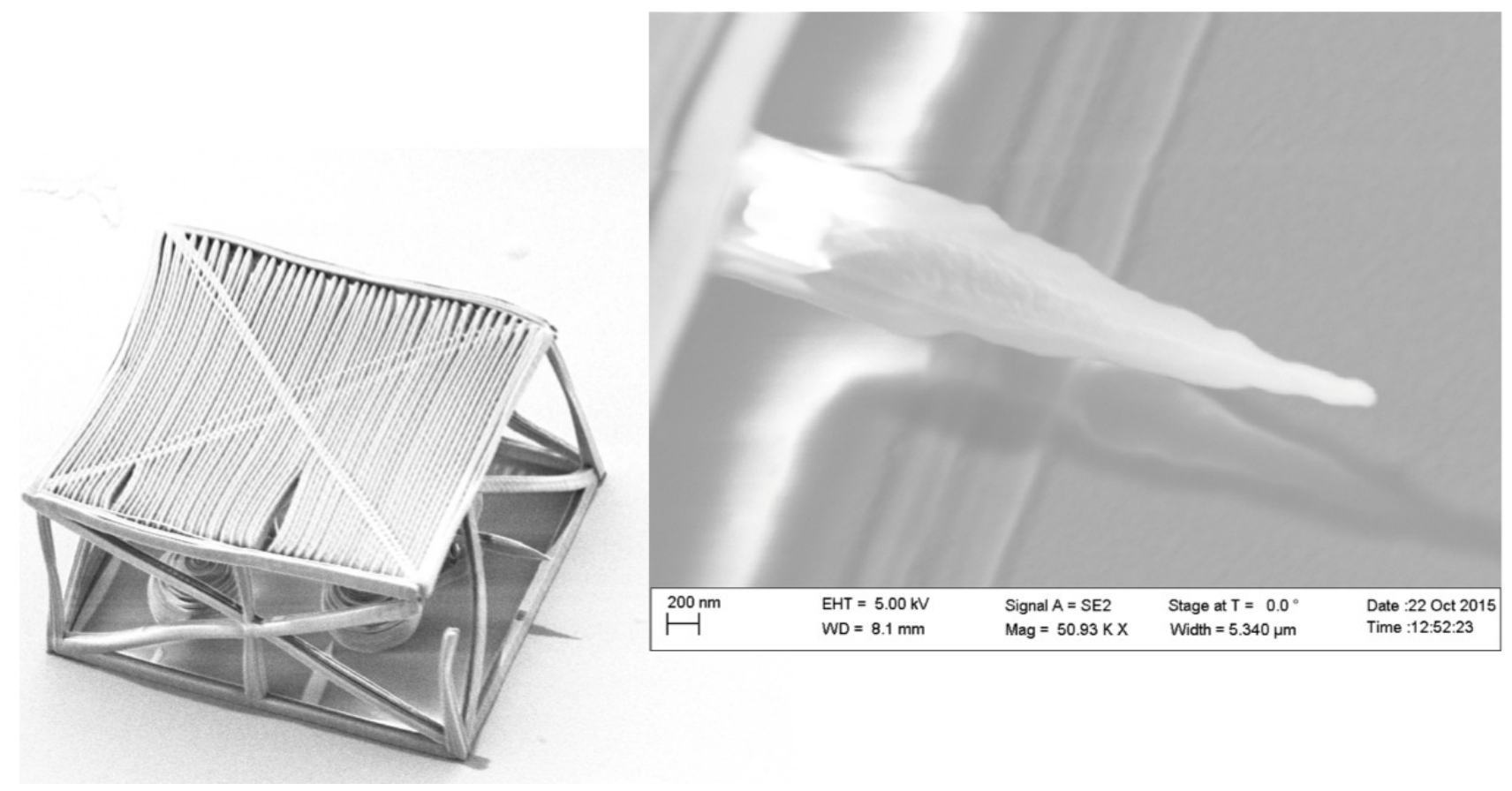

Fig. 5: SEM of a metal-coated tip-tool with a 200-nanometer scale-bar

Furthermore, light-programmed mechanical stimuli from the tools can be used to explore molecular effects that e.g. can convert mechanical signals picked up by cell membranes and converted to biochemical responses deeper within cells. 

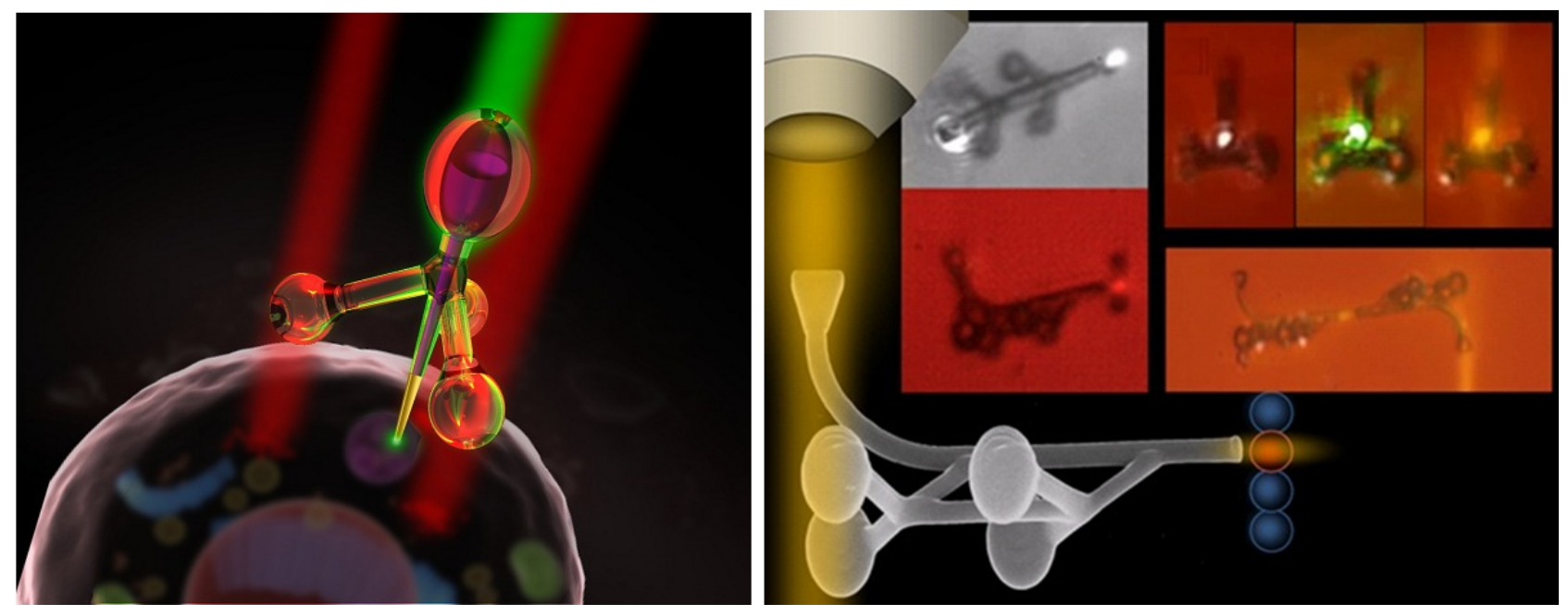

Fig. 6: Light Robotics acting like an artificial virus. Right: experiments adapted from ref. 16

Fig. 6 illustrates one of our future aims of fabricating and demonstrating the world's first artificial optical virus to perform a variety of light-actuated robotic functionalities on e.g. a living cell [17-22]. Preliminary test prints of such embodiments are SEM-imaged in Fig. 7 below.
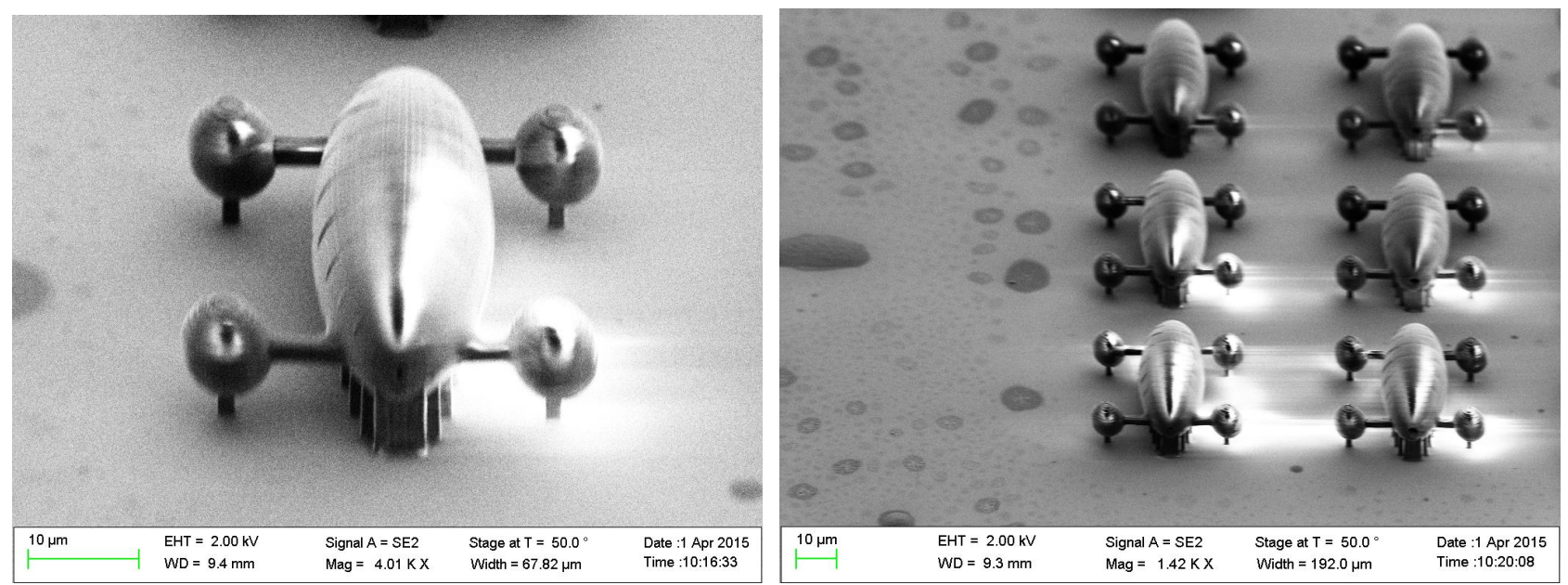

Fig. 7: Hollow micro-body structures fabricated for cargo-delivering Light Robotics 
The latest generation of our Light Robotic tools are capable of material transport and incorporates a syringe action for loading and unloading a tiny cargo. The used photoresist in the fabrication is practically transparent to the trapping beam wavelength and thus generates very little heat. On the other hand, metals are efficient energy-to-heat converters of light. Therefore, to enhance laserinduced heat generation in the photo-polymerized structures we embedded a thin metallic layer inside each of them using metal vapor deposition - i.e. Fig. 8. We used a 1 nano-meter titanium adhesion layer superposed by a 5 nano-meter gold layer deposited as a circular disk inside the body of each tool.
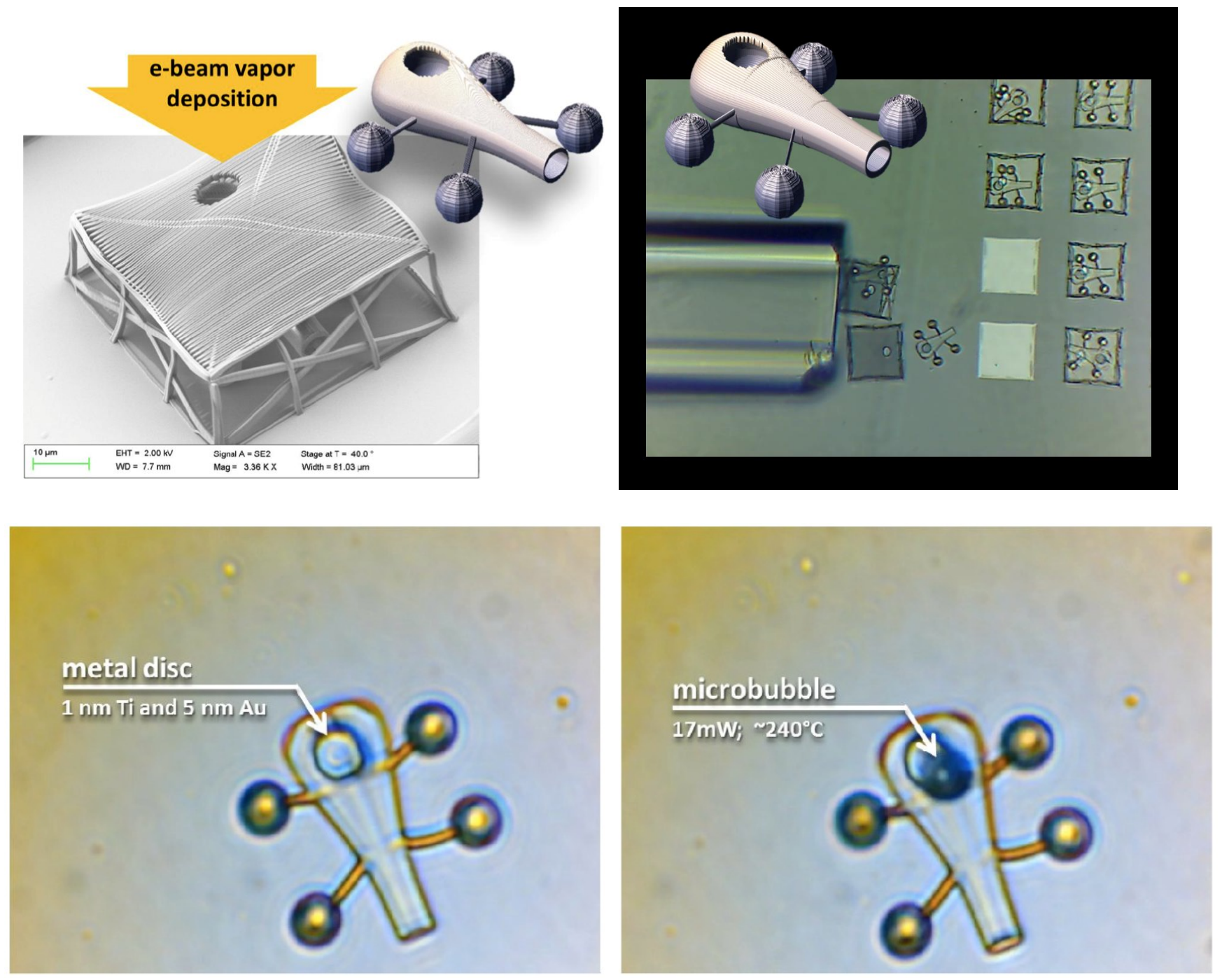

Fig. 8: Syringe-equipped light-driven micro-robotics. Adapted from ref. 20. 
The field of Light Robotics is still so new and promising that we have only just started to "scratch the surface" both scientifically and R\&D-wise. With the fast-paced development of new Augmented Reality tools such as e.g. Microsoft's Hololens, Artificial Intelligence and Machine Learning, advanced Swarm Robotics techniques and new 3D visualisation and manipulation modalities combined with state-of the-art Nano-biophotonics, the full scope of Light Robotics is obviously only in its infancy. Hence, we decided to edit a book volume including a variety of the ingredients needed to explore the full potential of Light Robotics and to trigger further rapid advancement of this exciting new research discipline. We hope to report on that in Yokohama later this Spring.

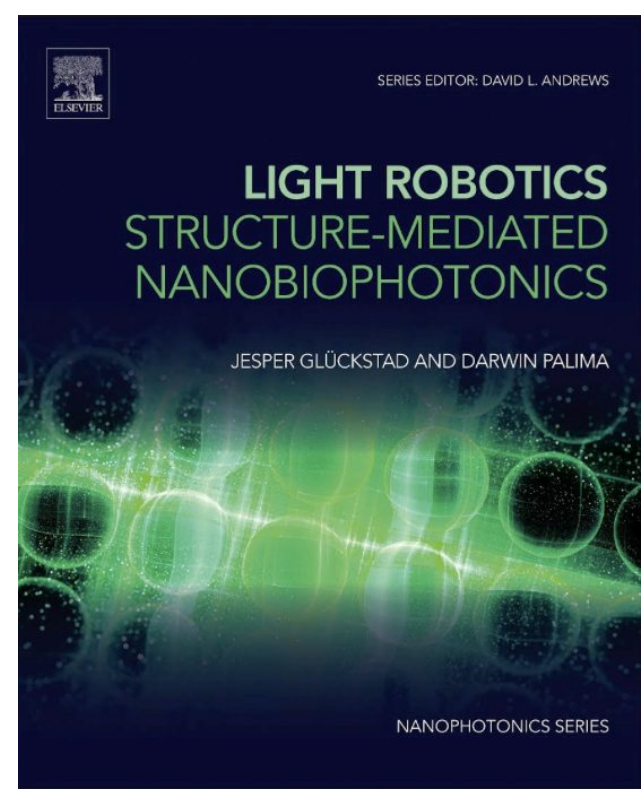

Fig. 9: Upcoming book on Light Robotics- the first on the topic.

\section{REFERENCES}

[1] Hell, S.W. "Far-Field, Optical Nanoscopy”, Science 316, 1153 - 1158 (2007).

[2] Rittweger, E., Han, K.Y., Irvine, S.E., Eggeling, C. and Hell, S.W., "STED microscopy reveals crystal colour centres with nanometric resolution", Nature Photonics 3, 144-147 (2009).

[3] Kawata, S., Sun, H. B., Tanaka, T. and Takada, K., "Finer features for functional microdevices", Nature 412, 697 (2001).

[4] Tan D. F., Li Y., Qi, F. J., Yang H., Gong, Q. H., Dong X. Z. and Duan X. M., "Reduction in feature size of two-photon photo-polymerization using SCR500", Appl. Phys. Lett. 90, 071106 (2007).

[5] Ashkin, A., “Acceleration and Trapping of Particles by Radiation Pressure," Phys. Rev. Lett. 24, 24-27 (1970).

[6] Glückstad, J., "Optical manipulation: Sculpting the object," Nature Photonics 5, 7-8 (2011). 
[7] Palima, D ., Glückstad, J., "Gearing up for optical microrobotics: micromanipulation and actuation of synthetic microstructures by optical forces," Laser and Photon. Rev. 7, 478-494 (2013).

[8] Rodrigo, P. J., Gammelgaard, L., Bøggild, P., Perch-Nielsen, I., Glückstad, J., “Actuation of microfabricated tools using multiple GPC-based counterpropagating-beam traps," Opt. Express 13, 6899-6904 (2005).

[9] Carberry, D. M., Simpson, S. H., Grieve, J. A., Wang Y., Schäfer, H., Steinhart M., Bowman, R., Gibson, G. M., Padgett M. J., Hanna S., and Miles, M. J., "Calibration of optically trapped nanotools", Nanotechnology 21, 175501 (2010).

[10] Ikin, L. Carberry, D. M., Gibson, G. M., Padgett, M. J., and Miles, M. J., “Assembly and force measurement with SPM-like probes in holographic optical tweezers, New J. Phys. 11, 023012 (2009).

[11] Rodrigo, P. J., Kelemen, L., Palima, D., Alonzo, C., Ormos, P., Glückstad, J., “Optical microassembly platform for constructing reconfigurable microenvironments for biomedical studies," Opt. Express 17, 6578-6583 (2009).

[12] Wu, C.W., Palima, D., Novitsky, A; Ding, W., Gao, D., Shukovsky, S., and Glückstad, J., "Engineering light-matter interaction for emerging optical manipulation applications," Nanophotonics 3, 181-201 (2014).

[13] Villangca, M., Casey, D., Glückstad, J., "Optically-controlled platforms for single- and subcellular transfection and surgery," Biophysical Reviews 7, 379-390 (2015).

[14] Mannix R.J., Kumar S., Cassiola F., Montoya-Zavala M., Feinstein E., Prentiss M., Ingber D.E., "Nanomagnetic actuation of receptor-mediated signal transduction", Nature Nanotech 36-40 (2008).

[15] Wozniak, M. A. and Chen, C. S., "Mechanotransduction in development: a growing role for contractility", Nature Reviews Molecular Cell Biology 10, 34-43 (2009).

[16] Palima, D., Bañas, A., Vizsnyiczai, G., Kelemen, L., Ormos, P., Glückstad, J., "Wave-guided optical waveguides," Opt. Express 20, 2004-2014 (2012).

[17] Villangca, M., Bañas, A., Palima, D., Glückstad, J., "Dynamic diffraction-limited light-coupling of 3D-maneuvered wave-guided optical waveguides," Opt. Express 22, 17880-17889 (2014).

[18] Villangca, M., Bañas, A., Palima, D., Glückstad, J. "Generalized phase contrast-enhanced diffractive coupling to light-driven microtools," Opt. Eng. 54, 111308 (2015).

[19] Palima, D., Bañas, A., Vizsnyiczai, G., Kelemen, L., Aabo, T., Ormos, P., and Glückstad, J., "Optical forces through guided light deflections," Opt. Express 21, 581-593 (2013).

[20] Villangca, M., Palima, D., Bañas, A., Glückstad, J., "Light-driven micro-tool equipped with a syringe function," Light: Science \& Applications 5, e16148 (2016).

[21] Bañas, A., Glückstad, J., "Holo-GPC: Holographic Generalized Phase Contrast," Optics Communications 392, 190-195 (2017).

[22] Glückstad, J., Palima, D., "Light Robotics - Structure-mediated Nanobiophotonics," Elsevier Science, 468 pages (2017). 